\section{Coordinated action needed for Europe's research programmes}

Plans are under way for integrated European research infrastructures that will foster synergy and collaboration among Europe's scientists (see go.nature. com/fsnB7a). The European Strategy Forum on Research Infrastructures (ESFRI) has put forward more than 40 priority projects, but these will be hard to implement without extensive European cooperation, even on a realistic timescale of 10-15 years.

Construction and running costs must be financed by national mechanisms, which will be difficult if every project applies to all 37 ESFRI member states and requires a separate national decision, as is now planned. Without coordinated action between the ESFRI member states and the European Commission, this process will be chaotic, inconsistent, costly and time-consuming.

A European decisiontaking body of member-state representatives could be set up that would implement agreed member-state policy on prioritization, funding, site selection and construction of the projects, while ensuring that legitimate national interests are taken into account. European countries could, for example, act together to equip the ESFRI with the extra responsibilities necessary to realize its plans.

Integration of existing expertise into the planning of the ESFRI projects could be improved. As well as developing appropriate legal and governance systems, the new research infrastructures will have to mobilize, recruit and train specialist staff to operate them.

Several European institutions have already solved these problems. The intergovernmental EIROforum organizations that operate some of Europe's existing international research infrastructures have governance designed for international membership and operation, and sustainable, performancebased funding systems. These should serve as models for the new research infrastructures and as sources of expert advice (see Establishing New Research Infrastructures in Europe - The EIROforum Experience; available at go.nature.com/4JfVEj).

Iain W. Mattaj European Molecular Biology Laboratory, Meyerhofstrasse 1, 69117 Heidelberg, Germany e-mail:mattaj@embl.org

\section{More patent protection for medicines with a new purpose}

You are right to urge the US government and others to encourage the re-use of old medicines by granting exclusivity rights (Editorial, Nature 465, 267; 2010). But it is not correct to say that the European Union (EU) already rewards innovators in this area with a further year of patent protection.

The EU awards an extra year's exclusivity for the technical data that are used to obtain the marketing authorization for the product, as long as the indications constitute a "significant clinical benefit". Because data exclusivity usually expires before patent protection, this provision is of limited value.

One solution would be for regulators to extend patent life when existing medicines have been repurposed for new uses - but this would only assist projects undertaken by the original patentee.

Another would be to exclude generic products from the market for a limited period should a third party, or the patentee, repurpose a medicine. The repurposed use could be assessed according to similar criteria and judged against new indications of significant clinical benefit (where these do not amount to repurposing). However, this would still not protect companies in situations in which generic products are already on the market.

Also, holders of repurpose patents could be allowed to enforce the patent when generic off-label use is damaging their monopoly.

Gareth Morgan DLA Piper LLP, 3 Noble Street, London EC2V 7EE, UK e-mail: gareth.morgan@dlapiper.com

\section{Closure threat to key museum research facility}

As leading representatives of the environmental and Earth science communities, we are gravely concerned about the proposed closure of the micropalaeontology research group at London's Natural History Museum (see go.nature.com/KCppCe).

Micropalaeontology is of considerable strategic and international importance. It underpins biological and geochemical proxy reconstructions of past climates. It is critical for industrial oil and gas exploration. It allows the evolutionary and palaeobiological study of organisms that have the most complete fossil record. The museum's micropalaeontology research group has made acclaimed contributions in all of these areas.

Loss of this expertise will compromise research in these fields and the training of the next generation of industry and research micropalaeontologists.

We accept that the Natural History Museum's researchers are not directly responsible for collections management. But micropalaeontologists are needed to interface with the many professional users of the museum's resources. The use and development of its micropalaeontology collection is likely to suffer in the long term as a result of the research group's closure.

The museum's trustees and director are being forced to respond to funding constraints that will require savings to be made across all departments. Instead of closing a whole research group with such key expertise, we urge the museum's management to produce a more balanced set of proposals that will be less damaging to palaeoclimate research, industrial biostratigraphy and evolutionary palaeobiology (see also go.nature.com/Eo4Thh).

Harry Elderfield Department of Earth Sciences, Cambridge CB2 3EQ, UK e-mail:he101@esc.cam.ac.uk Ulf Riebesell Leibniz Institute of Marine Sciences, 24105 Kiel, Germany John Raven Division of Plant Sciences, Invergowrie, Dundee DD2 5DA, UK Jean-Pierre Gattuso Observatoire Océanologique, F-06234 Villefranchesur-mer CEDEX, France Jere Lipps Department of Integrative Biology \& Museum of Paleontology, California 94720, USA

\section{Gender agenda: let's track women's trial participation}

Your discussion of sex bias in biomedical research (Nature 465, 665 and 688-690; 2010) doesn't mention the poor basic monitoring of female participation in clinical trials. Only the Office of Research on Women's Health in the United States systematically collects and publishes such data, and its statistics relate solely to publicly funded research.

The research community needs to be able to access participation data easily so that nuanced analysis of inclusion patterns can be conducted - for example, to take account of the proportion of women in non-sex-specific research. A simple solution would be for clinical-trials registries to collect data on the sex of participants.

Angela Ballantyne Department of Primary Health Care \& General Practice, University of Otago, Wellington 6242, New Zealand e-mail: angela.ballantyne@otago.ac.nz Wendy Rogers Department of Philosophy; and Australian School of Advanced Medicine, Macquarie University, NSW 2109, Australia 